An International Journal

Accepted Manuscript

$>$ Supports Open Access

Editor-in-Chief: Charla Griffy-Brown

$>$ View Editorial Board

- In Press

ISSN: 0160-791X

\title{
Love drugs: Why scientists should study the effects of pharmaceuticals on human romantic relationships
}

\author{
Brian D. Earp \& Julian Savulescu \\ University of Oxford
}

This is the authors' copy of an accepted paper, now in press. Please cite as:

Earp, B. D. \& Savulescu, J. (2017). Love drugs: Why scientists should study the effects of pharmaceuticals on human romantic relationships. Technology in Society, in press. Available at https://www.academia.edu/21966987/Love drugs Why scientists should study the effects of p harmaceuticals_on_human_romantic_relationships.

\begin{abstract}
There is ongoing disagreement about the moral implications of developing and/or using neurotechnologies that would affect romantic love and relationships. In this paper, we argue that scientists should actively pursue a research program into such technology. Our call for research is based in part on the fact that a number of pharmaceuticals already in use are very likely to have ramifications for our relationships (romantic and otherwise); and we suggest that we should attempt to understand the effects of these drugs on our interpersonal commitments. In a similar vein, we argue for a shift in scientific research norms, according to which the study of relationships and other social factors would be given higher priority than they are currently given. Finally, in an Appendix, we discuss our use of the term "love drug," and consider whether it is appropriate in light of debates about neuroreductionism.
\end{abstract}

Key words: love drugs, neuroenhancement, medicalization, pharmaceuticals, relationships, science 


\section{Introduction}

Over a series of papers, ${ }^{1}$ we have offered a limited defense of what we have been calling "love drugs" and "anti-love drugs." Roughly, we intend these terms to refer to current and nearfuture technologies that would enhance or diminish, respectively, the romantic bond between individuals in the context of an extant relationship (see the Appendix for further discussion). While the aim of our defense has been different in different papers - ranging from the right of couples to use such drugs, should they become available (Savulescu \& Sandberg, 2008), to the obligation that some parents may have, in the future, to take them (Earp et al., 2012) - in this paper, we are going to focus on an argument which we have not yet advanced directly: namely, that scientists should actively pursue a research program into the effects of pharmaceuticals and other brain-level interventions on romantic relationships, and that significant funding should be allocated for this purpose.

\section{Background}

In some of our earlier work, we trained our attention on a narrow question: that of permissibility. We asked: Are there any cases in which it would be morally permissible to take a drug — or employ a technology, etc. - that would either strengthen or help to break down a romantic bond, depending on the desired outcome? By thinking through various hypothetical scenarios (such as the case in which a victim of domestic abuse, who is uncontrollably in love with her abuser, might voluntarily take an "anti-love" drug to sever her emotional ties) ${ }^{2}$ we came to answer in the affirmative. That is, we identified a number of cases that, in our view, could morally justify the use of love-altering biotechnology given certain constraints and conditions.

Responses were mixed. Some commentators largely agreed with our reasoning concerning the cases we explored, while others took issue with our assumptions or conclusions. For example, in response to the domestic abuse scenario, Diana Aurenque and Christopher McDougall (2013) wrote, "The first and most obviously justified intervention in [this] case is ... not to drug the woman into unfeeling, but to alert the authorities to the violence and refer her to supportive social and legal services" (p. 35). This objection calls attention to the vital issues of social context and alternatives to drug-based interventions, which we have discussed at length in

\footnotetext{
${ }^{1}$ Chiefly: Earp (2012); Earp, Sandberg, and Savulescu (2012); Wudarczyk, Earp, Guastella, and Savulescu (2013); Earp, Wudarczyk, Sandberg, and Savulescu (2013); Earp, Sandberg, Savulescu, and Andersen (2013); Robson and Earp (2014); Earp, Sandberg, and Savulescu (2014); Savulescu and Earp (2014); Earp and Savulescu (2016); Earp, Sandberg, and Savulescu (2015, 2016); Vierra and Earp (2015); Earp, Wudarczyk, Foddy, and Savulescu (in press); Earp, Foddy, Wudarczyk, and Savulescu (in press); Earp and Hauskeller (2016).

${ }^{2}$ See Earp, Wudarczyk, Sandberg, and Savulescu (2013).
} 
a separate publication (Earp, Sandberg, \& Savulescu, 2015; see also Earp, Douglas, \& Savulescu, in press). The point here is that the debate concerning individual cases is ongoing, and that different scholars have taken, and will presumably continue to take, different stances with respect to each one.

For the purposes of the present essay, then, let us just assume that the "narrow" question has a positive answer: let us assume, that is, that there are indeed at least some cases in which the use of love drugs or anti-love drugs by an individual or couple would be morally permissible.

\section{Implications}

What follows from this? Does it follow that such drugs should be made widely available? That society would be better off, on balance, if they were? That their use, even in "permissible" cases, is necessarily desirable? By no means. As we have argued previously, societies are under no obligation to develop, much less make easily obtainable, the kind of technologies we have in mind, just so that they could be used for what we have argued are "permissible" purposes. Thus, "even though we think that mature individuals - that is, individuals who have not been brainwashed, who are competent to reason about their own goals and values, and who are meaningfully autonomous in their decision making — should be permitted," in principle, "to modify themselves pharmacologically in the ways we have described, it does not follow that there are no other reasons why societies might justifiably seek to manage (or restrict access to) certain mind- and self-altering substances" (Earp, Sandberg, \& Savulescu, 2014, p. 11).

Nevertheless, a sober discussion about the ethics of such technology should not be put off until tomorrow. For, even if it could be shown that the development of relationship-affecting neurointerventions would be "too fraught with risk to be worth pursuing deliberately," or would have negative consequences, on balance, for society, "it still might not be possible to avoid having to deal with their eventual existence." This is because advances in other areas, such as the development of novel treatments for brain disorders that affect socio-sexual functioning, might leave us "with the very same neuroscientific insights and/or technological capabilities that we would have ended up with had we sought them out for love-altering purposes directly." In such a scenario, "we would still have to ask ourselves whether, when, or to what extent to use the powers we had (inadvertently) created" (Earp, Sandberg, \& Savulescu, 2014, p. 5).

This is a precautionary approach. It emphasizes the prudence of "thinking ahead" about possible future scenarios, so that we might be prepared, socially and ethically, for their eventual occurrence, without taking a stand on whether the purposive investigation of relationship 
neuroenhancement ${ }^{3}$ is actually desirable. In this paper, however, we take a stand. Specifically, rather than merely suggesting that we should develop a robust moral framework concerning love drugs and anti-love drugs — just in case they are inadvertently developed — we will argue instead that scientists should deliberately pursue a research program into relationship-affecting neurotechnologies, and that this should be a funding priority.

\section{Motivation}

Our call for research is motivated by two key issues. First, as we will argue, it is likely that a number of pharmaceuticals already in use (i.e., for therapeutic purposes) are having unintended, and largely unrecognized, effects on human romantic relationships, and perhaps even experiences of love, ${ }^{4}$ some of which are bound to be detrimental. Scientists should study these effects, we argue, by broadening their attention from pathologies occurring, ostensibly, at the level of the individual (and their specific treatment in terms of associated symptoms), to the consequences of therapeutic drug use for relationships, considered in a socially-embedded context. $^{5}$

Second, and related to this issue, is the fact that the quality of people's relationships, including their romantic relationships, is one of the most powerful known predictors of good health and subjective well-being (see Wudarczyk et al., 2013 for a review). Indeed, “close personal relationships" also feature prominently in objective-list theories of well-being (e.g., Parfit, 1984; Griffin, 1986), calling attention to the fundamentally social character of human nature (Aronson, 2003; Adolphs, 2003). And as Nyholm (2015) has recently emphasized, such relationships may even be intrinsic goods or ends in themselves. Insofar as scientific and intellectual resources should be directed at increasing the likelihood of human flourishing, then, it seems to us that investigations into the causal determinants of relationship quality-including,

\footnotetext{
${ }^{3}$ There is ambiguity in our use of the word "neuroenhancement" in this sentence. As we argued in a recent paper, the definition of "enhancement," neuro- or otherwise, should be tied to the normative goal of the intervention being analyzed - typically, the promotion of individual (or couple) well-being (Earp, Sandberg, Kahane, \& Savulescu, 2014). On this account, the diminishment of a lower-level feeling, function, or capacity, such as might be accomplished by the use of an "anti-love" drug (in cases where such use would be appropriate), could plausibly improve — or "enhance" - the person's overall well-being. In that case, the "diminishing" intervention would actually count as a form of welfare enhancement on our preferred definition of the term (see also Savulescu, Sandberg, \& Kahane, 2011; Zohny, 2014).

${ }_{5}^{4}$ See Appendix for further discussion.

${ }^{5}$ Such a shift, we believe, would have important implications for pharmaceutical research going far beyond this specific debate concerning love drugs and anti-love drugs. Indeed, there are many good arguments, coming from a range of perspectives, that would favor the establishment of a research norm that prioritizes the investigation of interpersonal, social, and population-level effects of pharmaceuticals and other similar interventions - not just their effects on individuals and their symptoms.
} 
but by no means limited to, those which may be understood ${ }^{6}$ at the level of psychobiologyshould be a top priority.

For example, if it were shown that certain commonly used pharmaceuticals presented a high risk of degrading relationship quality (as a side-effect of the intended outcome), then their widespread prescription should be re-examined. Similarly, if other drugs, or the same drugs under different conditions, were shown to improve relationship quality on balance - as assessed in terms of the considered values of the couple in question, ideally in consultation with a trained therapist, and in the context of a structured counseling program - then their potential for therapeutic use should be looked into as well (Wudarczyk et al., 2013). ${ }^{7}$

To develop these points, we will proceed as follows. First, we will discuss a class of drug that is currently in widespread use, primarily for individual-level therapeutic purposes, but which is also likely to have ramifications for romantic relationships, namely selective serotonin reuptake inhibitors (SSRIs), commonly used as anti-depressants. Then we will discuss hormonal birth control, often referred to as "the pill," although we will not explore that example at length. Along the way, and continuing into a concluding section, we shall draw some lessons from these examples for the debate on the neuroenhancement of relationships, and discuss what we see as a need for a broader shift in scientific research norms.

\section{Discussion}

It is well established that drug-based treatments can have side-effects (see Etkin, 1992, for a thoughtful discussion). These are typically understood as unintended, and usually unwanted, physical or mental outcomes that affect the individual taking the drug (Stedman, 1982). Some of these potential side-effects may be known to the drug manufacturer; others may occur without having been formally documented, much less studied in a systematic manner. As Neil Levy and his colleagues (2014) have recently shown, "there are a number of pharmaceuticals already being

\footnotetext{
${ }^{6}$ As Ferraro (2015) notes, love in the context of romantic relationships is not "an ahistorical 'thing' within a neural and physiological domain, but rather, its points of reference [are] cultural, symbolic, linguistic, and contextual" (p. 487). We agree. Yet while the neural and physiological dimensions cannot wholly encompass love, they are not irrelevant to it either, as we discuss in the Appendix. Understanding the effects of various drugs on love and relationships, therefore, will require looking across domains and contexts: neural, psychological, interpersonal, cultural, historical, philosophical, and so on. Indeed, it is the interaction - and causal and conceptual bridgesbetween these variables that will be necessary for making predictions about the implications of any given drug for a given type of relationship, and there will be, as well, an irreducibly subjective element to consider (i.e., in terms of the individuals' own experiences and interpretations of love, and the meanings, etc., they ascribe to those experiences).

${ }^{7}$ Here, we are using the term "therapeutic" in its sense of having a positive effect on the body or mind, or contributing to a feeling or state of well-being. This is as opposed to the sense of "healing a disease" whereby a specific pathology must be present. For further discussion, see Earp, Sandberg, and Savulescu (2015).
} 
used on a large scale which affect human cognition and emotion" in ways that have not been adequately researched. Analyzing how these pharmaceuticals might alter our psychology, they argue, is "a pressing task, yet it is a task on which surprisingly little effort has been expended" (pp. 111-112).

We agree with this perspective. ${ }^{8}$ However, we suggest that it needs to be taken even further. Not only is there an urgent need, we argue, to study the effects of pharmaceuticals and other brain-level interventions ${ }^{9}$ on individual-level psychological processes — such as moral judgment and decision-making, as emphasized by Levy et al._-but there is also a need to study the effects of such neurotechnologies on relationships.

To make this point, we draw on the work of Helen E. Fisher and J. Anderson Thomson Jr. (2007), who have published a detailed chapter discussing just this issue. As they argue, some widely-used pharmaceuticals can have "serious psychological, social, and genetic consequences" for human romantic relationships, in part "through their effects on several ... neural mechanisms that evolved to enable mate assessment, mate choice, mate pursuit, feelings of romantic love, and expressions of attachment to a long term partner" (Fisher \& Thomson Jr., 2007, p. 245).

We shall start with the example emphasized by these authors - namely, SSRIs - and then follow with a brief discussion of hormonal birth control.

\section{Selective Serotonin Reuptake Inhibitors (SSRIs)}

SSRIs are typically prescribed for the treatment of depression as well as a wide range of anxiety disorders. Their name is derived from the fact that they block the re-uptake of serotonin in the presynaptic nerve terminal, thereby increasing its activity at the synapse. According to Laura Pratt and colleagues (2011), between 2005 and 2008, approximately 11\% of Americans ages 12 and older were on some form of anti-depressant, with SSRIs being the most commonly prescribed form (Mayo Clinic, 2013). While these drugs can be helpful, in many instances, in treating individuals' symptoms of depression, thereby allowing them to function more effectively in their day to day lives, including in some cases in the context of their relationships (see later discussion), they may also have negative interpersonal effects that are not very well understood.

For example, it has long been known that SSRIs can lower libido, which is centrally relevant to many romantic partnerships (although the specific implications for any particular

\footnotetext{
${ }^{8}$ Indeed one of us, Savulescu, is a co-author on the paper in question.

${ }^{9}$ Such as so-called non-invasive brain stimulation: see, e.g., Davis and van Koningsbruggen (2013), Maslen et al. (2014).
} 
couple will differ from case to case; see Box 1), but there is now emerging evidence that they can, in addition, dull what might be considered higher-level emotional states, such as caring about the feelings of others (e.g., Opbroek et al., 2002; Read et al., 2014). As Dixie Meyer (2007) has argued, the "overall lack of emotional stimulation" produced by SSRIs in some patients "may produce a blandness that overwhelms the romantic relationship" (p. 395). Nikki Graham (2010) has made the point somewhat more bluntly: "Aside from ruining your sex life," she writes, "antidepressants could also be responsible for breaking your heart" (p. 20).

\section{Box 1. What are the implications of a diminished libido on romantic relationships?}

What are the implications of a lowered libido for romantic relationships? Plainly, it depends upon the details. Consider, for example, that SSRIs have been prescribed off label as a treatment for what is sometimes referred to as "premature ejaculation," due to their ability to delay orgasm in some individuals (e.g., Balon, 1996; Waldinger et al., 2005). For couples for whom an extended period of intercourse or other sexual activity prior to ejaculation is judged to be desirable, and who struggle to achieve this goal by other means, SSRIs that make it harder to ejaculate may, in some cases, have a welcome effect all else being equal. For other couples, the very same outcome, namely, a delay or difficulty in achieving orgasm, may be judged to be undesirable, for any number of reasons. Speaking generally, then, a "diminished libido" (or other similar outcome), considered as a potential side-effect SSRIs, is neither inherently pathological nor even necessarily problematic. Rather, the character, intensity, and expression of people's sexual drives and capacities range widely even without the influence of medication (see Gupta, 2012, for a nice discussion). Whether a given alteration to those factors is likely to frustrate, or facilitate, one's relationship goals, therefore, will depend upon the type and degree of alteration, the means by which it is achieved, the nature of the relationship and the relationship goals themselves, etc.- -all considered within the context of other possible means by which those goals could be achieved, the sexual and other preferences of the couple in question, and their shared values. For related discussions, see Earp (2016) and Earp and Darby (in press).

Fisher and Thomson Jr. (2007) highlight several potential mechanisms by which SSRIs can negatively affect romantic relationships. These include the development of adverse sexual side effects (such as impotence) via interference with testosterone levels, which can lead to "performance anxiety" and thereby the avoidance of intimate situations. In addition to higherlevel psychological consequences and changes in the couple's dynamic, such avoidance can also lead to chronically lowered levels of oxytocin, a neuropeptide which is normally released through kissing, sensual touch, and orgasm, and which is strongly implicated in the formation and long-term maintenance of attachment bonds in humans and other animals (e.g., Feldman, 2012). Moreover, increased levels of serotonin caused by SSRIs can directly suppress activity in pathways for dopamine and norepinephrine, neurotransmitters which are involved in the production of subjectively reportable "feelings of romantic love" (Fisher \& Thomson Jr., 2007, p. 257)

To illustrate some of these potential effects in a more relatable manner, Fisher and Thomson Jr. share a number of "case studies." Consider the following apparently real-life 
account of a 26-year-old man who had panic attacks that required high doses of an SSRI:

He soon experienced diminished libido and impotence. A handsome, personable, intelligent man, he was readily sought after by women. However, he ended several relationships because he was too embarrassed about his inability to perform sexually. Although he tried several other medications, he was able to control his panic disorder only with high doses of serotonin enhancers. Eventually he retreated into a social life in which he avoided serious dating. When last evaluated he still confined himself to nonsexual relationships with women. (Fisher \& Thomson Jr., 2007, p. 267)

Elsewhere, they quote from a letter published in the New York Times (Frankel, 2004):

After two bouts of depression in 20 years, my therapist recommended I stay on serotoninenhancing antidepressants indefinitely. As appreciative as I was to have regained my health, I found that my usual enthusiasm for life was replaced with blandness. My romantic feelings for my wife declined drastically. With the approval of my therapist, I gradually discontinued my medication. My enthusiasm returned and our romance is now as strong as ever. I am prepared to deal with another bout of depression if need be, but in my case the long-term side effects of antidepressants render them off limits.

Not everyone reports similar experiences, however. Consider this very different account from a couple that was recently profiled for a story in Elle magazine (Kamps, 2012):

Before they got on antidepressants, Susan's tendency to rail at length (about whatever happened to be irking her) exacerbated Will's "extremely self-critical" tendencies: "Whereas in her depression she'd tend to lash out, in mine I'd tend to sink inward," he says. ... "We were heading down a bad path." Now, though, they agree their marriage is much better balanced. Susan's rough edges have "softened," as Will puts it, and with this - plus the boost medication has given his own confidence- he's become more forthcoming: They're able to work together to solve problems. "We really are each other's best partners," Will says. "To call us soul mates I think would be accurate."

The lesson from these contrastive cases - which we acknowledge are merely anecdotes $^{10}$ - is that SSRIs (or other drugs) might put some relationships in jeopardy, while in other instances, they might serve as relationship enhancers. In this context, it should be noted that the connections between the sex drive, the attachment system, and higher-level experiences of romantic love, are complex and not entirely well understood. As Fisher and Thomson Jr.

\footnotetext{
${ }^{10}$ Anecdotes are among the least reliable forms of evidence for establishing clear causation. But that is consistent with our overall argument: our call is precisely for additional, more systematic research into the effects of pharmaceuticals on relationships, paying attention to the personal, interpersonal, and contextual variables that allow for the prediction of different outcomes (i.e., for different couples under different circumstances).
} 
explain, the interrelationship between these factors differs from person to person; it is also "dose dependent [and] varies depending on the quantities, timing, and interactions among several hormones." Thus, under some circumstances, "serotonin-enhancing antidepressants that suppress the sex drive [can actually] strengthen feelings of attachment in a long-term relationship," rather than weaken them, as discussed above (Fisher \& Thomson Jr., 2007, pp. 261-262).

A similar analysis is given by Levy et al. (2007) in their discussion of the effects of SSRIs on people's moral psychology. "Whether using a particular pharmaceutical induces morally better or worse decisions and behavior," they write, "depends, crucially, on the individual's pre-existing dispositions and the circumstances in which they act, as well as what the drug is used for and the effect of any underlying condition on moral decision-making and behavior" (p. 122).

Of course, it also depends on what is assumed, or argued, to be morally "better" versus "worse" in the first place, which is fundamentally a question of values. Thus, it is a question with respect to which different people will reach different conclusions - as Levy et al. acknowledge elsewhere in their paper. Likewise for love and relationships. In other words, even if a complete description of the physical and psychological effects of a given pharmaceutical (on an individual or couple with $\mathrm{X}, \mathrm{Y}$, and Z characteristics) could be "scientifically" determined, the question of whether it counted as a "love drug"- or as a relationship "enhancer" as opposed to the opposite-would still be open: it would depend upon, among other things, the couple's conception of love, their relationship goals, and their values (see Appendix for further discussion).

That said, scientists are currently nowhere close to a "complete description" of the "physical and psychological effects" of SSRIs - or any other widely-used drug — on either individuals or couples, much less over a range of conditions, personality traits, and relationship characteristics. All that is known at this point, as Fisher and Thomson, Jr. argue, is that the "flexible nature of [the] brain mechanisms for reproduction and their complex, dynamic interactions suggest that any medication that changes the chemical checks and balances is likely to alter an individual's courting, mating, and parenting tactics," with potentially wide-ranging implications for relationships (Fisher \& Thomson, Jr., 2007, p. 269).

To say that further research is needed would be an understatement. And this research needs to be "fine-grained." As Levy et al. (2014) note, "we need to know not only the average effects of pharmaceuticals, but also how they interact with pre-existing dispositions of agents and the underlying condition for which they are being used." Problematically, however, "we lack 
sufficient knowledge of these factors with regard to an enormous number of widely used pharmaceuticals" (p. 122).

Hormonal birth control-a.k.a. "the pill"

One such pharmaceutical is "the pill." According to the U.S. Centers for Disease Control and Prevention, between 2006 and 2010, 62\% of American women of reproductive age were using contraception. The most common form of contraception employed-typically to prevent unwanted pregnancy — was hormonal birth control, used by 10.6 million women (CDC, 2012). Hormonal contraception refers to birth control methods that act on the endocrine system. Almost all methods consist of steroid hormones, and there are two main types: combined methods, which contain both estrogen and progestin, and progestin-only methods. Combined methods work by suppressing ovulation and thickening cervical mucus, while progestin-only methods reduce the frequency of ovulation (Storck, 2014).

Common side effects of progestin-only hormonal birth control include menstrual cycle disruption, headaches, weight gain, and breast tenderness (McCann \& Potter, 1994). Some forms of hormonal birth control can also cause nausea and mood swings, and may affect libido in some women as well (Littleton, 2015). While the latter of these effects could have indirect consequences for relationships (see Box 1), in recent years, a body of research has emerged which suggests - but by no means conclusively demonstrates - a more direct connection between hormonal birth control and so-called "mating preferences" in women (e.g., Alvergne, \& Lummaa, 2010).

According to one common theory, hormonal variation over women's menstrual cycles changes their preferences for outward indicators of men's genetic or parental quality (however, see the meta-analysis by Wood et al., 2014, which is largely non-supportive of this view), including signals that might be communicated unconsciously via pheromones (Grammer et al., 2005). Since hormonal contraceptives suppress this variation, the theory goes, different mate preference patterns might develop such that women who are using oral contraception in the early stages of dating could end up choosing a less genetically "fit" or compatible partner than they would do if they were not on birth control (see, e.g., Roberts \& Little, 2008).

In a recent study, S. Craig Roberts and colleagues (2012) tested this idea, looking for differences in relationship quality and eventual break-up between women who were or were not using oral contraception (OC) when they initially partnered with the man who fathered their first child. They found that women who were on hormonal birth control at the time "scored lower on 
measures of sexual satisfaction and partner attraction, experienced increasing sexual

dissatisfaction during the relationship, and were more likely to be the one to initiate an eventual separation if it occurred." Curiously, however, "the same women were more satisfied with their partner's paternal provision, and thus had longer relationships and were less likely to separate." As they concluded, "our results demonstrate that widespread use of hormonal contraception may contribute to relationship outcome, with implications for human reproductive behaviour, family cohesion and quality of life" (p. 1430). Just as with SSRIs, however, these implications are only barely beginning to be researched.

\section{Conclusion}

In this essay, we have emphasized a number of potential "downsides" that two widelyused pharmaceuticals may have for romantic relationships. But we have also hinted at possible "upsides" as well, depending upon the drug, the dose, the individual, and the particular couple involved. Given the centrality of close relationships to both subjective and objective accounts of human well-being, we suggest that scientists and funders should ${ }^{11}$ prioritize the investigation of these effects, so that we might "avoid the worst dangers" posed by pharmaceuticals to our romantic relationships, as well as perhaps "harness them to better ends" (Levy et al, 2014, p. 123).

To do this would require a shift in research norms. With respect to the effects of SSRIs, for example, as Kamps (2012) has noted: "Many standard measures of depression focus on mood-based symptoms such as sadness, withdrawal, and loss of appetite rather than on how respondents are getting along with spouses, coworkers, and kids." At the same time, negative and potentially harmful emotions such as (maladaptive) anger are "common in depression-and spouses tend to bear the brunt." Indeed, scientists' failure to appreciate this interpersonal dimension could be one reason why some studies suggest that "antidepressants don't work terribly well ... the data [don't] capture their ability to reduce volatility [in romantic relationships] because researchers don't ask about it in the first place."

\footnotetext{
${ }^{11}$ A reviewer asks what we mean by "should" here. We are fine with more than one interpretation. One way to read this is as a conditional: if scientists and funders think it is important to direct their resources toward improving human health and well-being, then they would be remiss to ignore the interpersonal dimensions of pharmaceutical and other medical interventions. Another way to read it is like this: scientists and funders have an obligation, all else being equal, to improve human health and well-being — and to minimize harm — when and insofar as they can. Therefore, they have an obligation to study the effects of widely-used drugs on relationships, since these may be causing significant harm and/or failing to provide as much benefit as they could.
} 
Our suggestion, quite simply, is that researchers should start to ask such questions. This could happen in a number of ways. Researchers could, themselves, decide to alter-or add tothe protocols they use to assess the outcomes of the drugs being tested. Funding agencies could encourage a greater emphasis on studying the interpersonal dimensions of drug-use when making decisions about grants. Pharmaceutical companies could be held to task for advertising drugs without first evaluating their social implications. Doctors could include questions about positive and negative effects on relationships when checking up on their patients' progress - and so on.

At bottom, we suggest that interpersonal health and well-being should be regularly assessed, using both qualitative and quantitative measures, as primary outcomes of interest in studies on the effects of pharmaceutical interventions. It is not enough to study individuals and their symptoms: each of us is embedded in at least some kind of social context, and if certain drugs are going to continue to be prescribed for therapeutic purposes, it is imperative that we understand their implications for our relationships. ${ }^{12}$

\footnotetext{
${ }^{12}$ A reviewer suggests that we have left an ambiguity 'lurking' behind our paper. Specifically, it is not clear whether the further research we are advocating "should aim at developing drugs that could intentionally be used to affect romantic relationships," or whether our concern "is just with understanding the side-effects [for relationships] of current drugs" that are being used for other purposes. For the sake of this paper, our concern is only the latter. For arguments in support of the former aim, readers can turn to our earlier papers (see footnote 1).
} 


\section{Appendix - What is a love drug, really? ${ }^{13}$}

When we give our lectures on "love drugs," someone usually sticks up her hand asks, "But what do you mean by 'love'?” Usually we demur, saying something like "Look, what we are focusing on here are the neurobiological underpinnings of human lust, attraction, and attachment, and how those systems relate to 'love' is going to depend on the specific theory of love one prefers." We don't want to be prescriptive, and say that we know what love "really is," nor do we want our ethical analysis to be tied to any single conception (see below). So we tend to use the term informally, not to mention expansively, to cover a wide range of possible definitions.

In fact, in our view, there is no Platonic definition of love, floating out there for someone to discover. Love has different meanings. As Karin Weis (2006) states, "Love is not a uniform phenomenon. There are countless variations on the forms [loving] relationships can take [and] just as diverse as the appearances of love are the theories of love that try to fathom it" (pp. 2-3). As the Oxford English Dictionary (2015) would have it, love is "a feeling or disposition of deep affection or fondness for someone, typically arising from a recognition of attractive qualities, from natural affinity, or from sympathy and manifesting itself in concern for the other's welfare and pleasure in his or her presence." To poets like Charles Burkowski, "Love is a fog that burns with the first daylight of reality" (see Popova, 2012). Ambrose Bierce (1911/1996) takes a more cynical view: "Love, n. A temporary insanity curable by marriage" (p. 162).

We confess that we see something of value in each of these definitions, as well as many others that could be given. That said, for the bulk of our research, we tend to focus on a psychobiological account of love (for a justification of this focus, see Earp, Sandberg, \& Savulescu, 2016, Box 1). This account suggests that the complex feelings, motivations, and interpersonal attachments that one would typically associate with the word "love" in a Western context are actually grounded in, and in fact emerge from, a suite of neurochemical and behavioral subsystems that evolved to promote the reproductive success of our ancestors (e.g., Kenrick, 2006; Carter, 1998; Fisher et al., 2006). How, precisely, these underlying systems relate to "higher level" conceptions and subjective experiences of love is not yet fully understood, and again, this relationship will depend almost entirely upon the specific higher-level conception one prefers. At the same time, unless one subscribes to a dualistic theory of the world, according to which love exists in something like a disembodied "soul," what is clear by now is that there is a

\footnotetext{
13 Portions of this Appendix are adapted from Box 1 of the essay, "If I Could Just Stop Loving You: Anti-Love Biotechnology and the Ethics of a Chemical Breakup” (Earp, Wudarczyk, Sandberg, \& Savulescu, 2013).
} 
relationship between these levels, and a significant one at that. Mess with the underlying systems - in a sufficiently disruptive way - and you mess with love, on almost any definition.

An analogy might be the Mona Lisa. There is a sense in which a technically complete description of this painting could be given in terms of splotches of paint occurring at various coordinates on a two-dimensional canvas. But most people would say that a really robust understanding of the Mona Lisa requires a whole range of different levels of analysis: how she appears to the person looking at her, something about the emotion expressed by her peculiar smile, what we know about the artist who made the painting, and so on. There are also different ways of understanding the painting based on the theory of art one subscribes to; these theories appeal to different people for different reasons, and they are not always entirely compatible.

At the same time, the low-level splotches of paint can't just be dismissed. For example, we know that changing those splotches of paint in certain ways - say, by coating all of the greencolored splotches with shades of hot pink-will also change the Mona Lisa. This is likely to be the case regardless of the higher-level theory of art one favors, although the precise way in which the painting can now be said to be different will depend on the particular theory (as well as on the chosen level or levels of analysis). In a similar vein, consider the issue of artistic restoration. As masterpieces like the Mona Lisa fade with time, they can sometimes be "touched up" to maintain their essential character. Just as with the green-to-pink transformation, this sort of alteration would have occur, on at least one level of description, by virtue of making concrete, physical changes to those lower-level splotches of paint - even though the particular changes that would be made in this new case would be quite different (no hot pink should be used for restoration). And here, too, there will be subjective value judgments as to what is really "essential" about the painting, and therefore what specific changes are needed to preserve the relevant features.

So too with love. Supplementing a marriage counseling session with oxytocin or MDMA (for practical details, see Wudarczyk et al., 2013, and Earp, 2015)_both of which work directly on the brain — might be judged by some couples to be a legitimate means of maintaining what is essential about the love between them. For other couples, however, the same intervention might be viewed as inauthentic means of doing so, resulting in a pseudo-love at best. Similarly, some theories of love will acknowledge that the loss of sexual interest in one's partner brought about by an SSRI - or the blunting of one's ability to feel sad about that partner's misfortune - is a bona fide "anti-love" effect. Other theories will reject this conclusion, saying that the love for 
one's partner has not changed, but only some low-level motivational state or emotional capacity that, while relevant, is not essential.

It has not been our interest to adjudicate such questions, nor to defend a "one size fits all" account of love. As we explained in a recent essay, we are much "less concerned about whether a given a given state of desire, attraction, etc., is deserving of the label 'love,' than with whether it is causing net harm to oneself or someone else, and, if it is, whether the application of a medical technology could ethically play a role in preventing or alleviating that harm" (Earp \& Savulescu, 2016, p. 94). Nevertheless, while talk of brain chemicals only gets us so far-in terms of getting a hold of what we really care about when we experience love, or attempt to describe it - there can be no doubt that such chemicals play a fundamental role in shaping, or giving rise to, those very same experiences and descriptions. ${ }^{14}$ More importantly, changing them (in the right kind of way) will also change the higher-level "love" accordingly_-depending upon the particulars of the couple in question, along with their physical, social, and historical context-however one wishes to define it.

\footnotetext{
${ }^{14}$ Similarly, our experiences, beliefs, and conceptions about love have the power to change our brain chemistry: just think about the sudden increase in adrenaline, for example, that might occur when one's beloved is seen, unexpectedly, in the arms of someone else. Think, too, about how that brain-level response might differ as a partial function of one's higher-level commitments: if one is passionate about polyamory, for example, or has carefully invested in an "open" relationship, then the very same perceptual event might not have the same effect on her lowerlevel neurochemistry.
} 


\section{References}

Adolphs, R. (2003). Cognitive neuroscience of human social behaviour. Nature Reviews Neuroscience, 4(3), 165-178.

Alvergne, A., \& Lummaa, V. (2010). Does the contraceptive pill alter mate choice in humans? Trends in Ecology \& Evolution, 25(3), 171-179.

Aronson, E. (2003). The social animal. New York: Macmillan.

Aurenque, D., \& McDougall, C. W. (2013). Amantes sunt amentes: Pathologizing love and the meaning of suffering. The American Journal of Bioethics, 13(11), 34-36.

Balon, R. (1996). Antidepressants in the treatment of premature ejaculation. Journal of Sex \& Marital Therapy, 22(2), 85-96.

Bierce, A. (1911/1996). The devil's dictionary. Ware: Wordsworth Editions.

Carter, C. S. (1998). Neuroendocrine perspectives on social attachment and love. Psychoneuroendocrinology, 23(8), 779-818.

CDC (2012, October 18) Current contraceptive use in the United States, 2006-2010, and changes in patterns of use since 1995. National Health Statistics Reports, 60, 1-25. Available at http://www.cdc.gov/nchs/data/nhsr/nhsr060.pdf

Davis, N. J., \& van Koningsbruggen, M. G. (2013). "Non-invasive" brain stimulation is not noninvasive. Frontiers in Systems Neuroscience, 7(76), 1-4.

Earp, B. D. (2012). Love and other drugs. Philosophy Now, Issue 91 (July/August), 14-17.

Earp, B. D. (2015). Drogen nehmen - um Wohl unserer Kinder? GEO Magazine, 10(1), 62-63. 
Earp, B. D. (2016). Infant circumcision and adult penile sensitivity: Implications for sexual experience. Trends in Urology \& Men's Health, 7(4), 17-21.

Earp, B. D. \& Darby, R. (in press). Circumcision, sexual experience, and harm. University of Pennsylvania Journal of International Law, in press.

Earp, B. D., Douglas, T., \& Savulescu, J. (in press). Moral neuroenhancement. In S. Johnson \& K. Rommelfanger (Eds.), Routledge Handbook of Neuroethics. New York: Routledge.

Earp, B. D., Foddy, B., Wudarczyk, O. A., \& Savulescu, J. (in press). Love addiction: Reply to Jenkins and Levy. Philosophy, Psychiatry, \& Psychology, in press.

Earp, B. D., \& Hauskeller, M. (2016). Binocularity in bioethics - and beyond. American Journal of Bioethics, 16(2), W3-W6.

Earp, B. D., Sandberg, A., Kahane, G., and Savulescu, J. (2014). When is diminishment a form of enhancement? Rethinking the enhancement debate in biomedical ethics. Frontiers in Systems Neuroscience, 8(12), 1-8.

Earp, B. D., Sandberg, A., Savulescu, J., \& Andersen, R. (2013, January 31). The case for using drugs to enhance our relationships (and our break ups). The Atlantic. Available at http://www.theatlantic.com/technology/archive/2013/01/the-case-for-using-drugs-to-enhanceour-relationships-and-our-break-ups/272615/.

Earp, B. D., Sandberg, A., \& Savulescu, J. (2012). Natural selection, childrearing, and the ethics of marriage (and divorce): Building a case for the neuroenhancement of human relationships. Philosophy \& Technology, 25(4), 561-587. 
Earp, B. D., Sandberg, A., \& Savulescu, J. (2014). Brave new love: The threat of high-tech "conversion" therapy and the bio-oppression of sexual minorities. American Journal of Bioethics: Neuroscience, 5(1) 4-12.

Earp, B. D., Sandberg, A., \& Savulescu, J. (2015). The medicalization of love. Cambridge Quarterly of Healthcare Ethics, 24(3), 323-336.

Earp, B. D., Sandberg, A., \& Savulescu, J. (2016). The medicalization of love: Response to critics. Cambridge Quarterly of Healthcare Ethics, 25(4), 759-771.

Earp, B. D., \& Savulescu, J. (2016). Is there such a thing as a love drug? Reply to McGee. Philosophy, Psychiatry, \& Psychology, 23(2), 93-96.

Earp, B. D., Wudarczyk, O. A., Sandberg, A., \& Savulescu. J. (2013). If I could just stop loving you: Anti-love biotechnology and the ethics of a chemical breakup. American Journal of Bioethics, 13(11), 3-17.

Earp, B. D., Wudarczyk, O. A., Foddy, B., \& Savulescu, J. (in press): Addicted to love: What is love addiction and when should it be treated? Philosophy, Psychiatry, \& Psychology, in press.

Etkin, N. L. (1992). "Side effects": Cultural constructions and reinterpretations of western pharmaceuticals. Medical Anthropology Quarterly, 6(2), 99-113.

Feldman, R. (2012). Oxytocin and social affiliation in humans. Hormones and Behavior, 61(3), 380-391.

Ferraro, D. (2015). On love, ethics, technology, and neuroenhancement. Cambridge Quarterly of Healthcare Ethics, 24(4), 486-489. 
Fisher, H. E., Aron, A., \& Brown, L. L. (2006). Romantic love: A mammalian brain system for mate choice. Philosophical Transactions of the Royal Society of London B: Biological Sciences, 361(1476), 2173-2186.

Fisher, H. E., \& Thomson Jr., J. A. (2007). Lust, romance, attachment: Do the side effects of serotonin-enhancing antidepressants jeopardize romantic love, marriage, and fertility? In S. Platek, J. Keenan, and T. Shackelford (Eds.), Evolutionary cognitive neuroscience, pp. 245-283. Cambridge: MIT Press.

Frankel, J. (2004, May 11). Reviving romance. The New York Times, p. F4, Letters.

Graham, N. (2010). Sex, love and serotonin. Health Intelligence: The Science of Health, 2, 2024.

Grammer, K., Fink, B., \& Neave, N. (2005). Human pheromones and sexual attraction. European Journal of Obstetrics \& Gynecology and Reproductive Biology, 118(2), 135-142.

Griffin, J. (1986). Well-being: Its meaning, measurement, and moral importance. Oxford: Clarendon.

Gupta, K. (2012). Protecting sexual diversity: Rethinking the use of neurotechnological interventions to alter sexuality. AJOB Neuroscience, 3(3), 24-28.

Jones, B. C., Perrett, D. I., Little, A. C., Boothroyd, L., Cornwell, R. E., Feinberg, D. R., ... \& Burt, D. M. (2005). Menstrual cycle, pregnancy and oral contraceptive use alter attraction to apparent health in faces. Proceedings of the Royal Society of London B: Biological Sciences, $272(1561), 347-354$.

Kamps, L. (2012, April 18). The couple who medicates together. Elle. Available at http://www.elle.com/life-love/sex-relationships/advice/a14208/the-couple-who-medicatestogether-654677/. 
Kenrick, D. T. (2006). A dynamical evolutionary view of love. In: R. Sternberg \& K. Weis (Eds.), The new psychology of love, 15-34. New Haven: Yale University Press.

Levy, N., Douglas, T., Kahane, G., Terbeck, S., Cowen, P. J., Hewstone, M., \& Savulescu, J. (2014). Are you morally modified? The moral effects of widely used pharmaceuticals.

Philosophy, Psychiatry, \& Psychology, 21(2), 111-125.

Littleton, M. W. (2015). The truth about "the pill" and your sex drive. Web MD (reviewed by Traci C. Johnson, MD, FACOG). Available at http://www.webmd.com/sex/birthcontrol/features/the-pill-and-desire.

Mayo Clinic Staff (2013, July 9). Depression (major depressive disorder). The Mayo Clinic. Available at http://www.mayoclinic.org/diseases-conditions/depression/in-depth/ssris/art$\underline{20044825 .}$

Maslen, H., Earp, B. D., Cohen Kadosh, R., \& Savulescu, J. (2014). Brain stimulation for treatment and enhancement in children: An ethical analysis. Frontiers in Human Neuroscience, $8(953), 1-5$.

McCann, M. F., \& Potter, L. S. (1994). Progestin-only oral contraception: A comprehensive review: X. Common side effects. Contraception, 50(6), S114-S138.

Meyer, D. (2007). Selective serotonin reuptake inhibitors and their effects on relationship satisfaction. The Family Journal, 15(4), 392-397.

Nyholm, S. (2015). The medicalization of love and narrow and broad conceptions of human well-being. Cambridge Quarterly of Healthcare Ethics, 24(3), 337-346.

Opbroek, A., Delgado, P. L., Laukes, C., McGahuey, C., Katsanis, J., Moreno, F. A., \& Manber, R. (2002). Emotional blunting associated with SSRI-induced sexual dysfunction. Do SSRIs 
inhibit emotional responses? The International Journal of Neuropsychopharmacology, 5(02), 147-151.

Oxford English Dictionary. (2015). Love, n. Oxford English Dictionary. Available at http://www.oed.com.

Parfit, D. (1984). Reasons and persons. Oxford: Oxford University Press.

Pratt, L. A., Brody, D. J., \& Gu, Q. (2011). Antidepressant use in persons aged 12 and over: United States, 2005-2008. NCHS Data Brief, 76, 1-8.

Popova, M. (2012, January 3). Charles Burkowski on what love is. Brain Pickings. Available at https://www.brainpickings.org/2012/01/30/charles-bukowski-on-love/.

Read, J., Cartwright, C., \& Gibson, K. (2014). Adverse emotional and interpersonal effects reported by 1829 New Zealanders while taking antidepressants. Psychiatry Research, 216(1), 6773.

Roberts, S. C., Klapilová, K., Little, A. C., Burriss, R. P., Jones, B. C., DeBruine, L. M., ... \& Havlíček, J. (2012). Relationship satisfaction and outcome in women who meet their partner while using oral contraception. Proceedings of the Royal Society B: Biological Sciences, 279(1732), 1430-1436.

Roberts, S. C., \& Little, A. C. (2008). Good genes, complementary genes and human mate preferences. Genetica, 132(3), 309-321.

Savulescu, J., \& Earp, B. D. (2014). Neuroreductionism about sex and love. Think: A Journal of the Royal Institute of Philosophy, 13(38), 7-12.

Savulescu, J., \& Sandberg, A. (2008). Neuroenhancement of love and marriage: The chemicals between us. Neuroethics, 1(1), 31-44. 
Savulescu, J., Sandberg, A., \& Kahane, G. (2011). Well-Being and enhancement. In: J. Savulescu, R. ter Meulen, \& G. Kahane (Eds.), Enhancing human capacities, 1-18. Hoboken: Wiley-Blackwell.

Stedman, T. (1982). Stedman's medical dictionary. Baltimore: Williams and Wilkins.

Storck, S. (2014). Birth control pills - overview. A.D.A.M. Medical Encyclopedia - U.S. National Library of Medicine. Available at https://www.nlm.nih.gov/medlineplus/ency/article/007460.htm.

Vierra, A., \& Earp, B. D. (2015, April 21). Born this way? How high-tech conversion therapy could undermine gay rights. The Conversation. Available at https://theconversation.com/bornthis-way-how-high-tech-conversion-therapy-could-undermine-gay-rights-40121

Waldinger, M. D., Schweitzer, D. H., \& Olivier, B. (2005). On-demand SSRI treatment of premature ejaculation: Pharmacodynamic limitations for relevant ejaculation delay and consequent solutions. The Journal of Sexual Medicine, 2(1), 121-131.

Weis, K. (2006). Introduction. In: R. Sternberg \& K. Weis (Eds.), The new psychology of love. New Haven: Yale University Press.

Wood, W., Kressel, L., Joshi, P. D., \& Louie, B. (2014). Meta-analysis of menstrual cycle effects on women's mate preferences. Emotion Review, 6(3), 229-249.

Wudarczyk, O. A., Earp, B. D. , Guastella, A., \& Savulescu, J. (2013): Could intranasal oxytocin be used to enhance relationships? Research imperatives, clinical policy, and ethical considerations. Current Opinion in Psychiatry, 26(5), 474-484.

Zohny, H. (2014). A defence of the welfarist account of enhancement. Performance Enhancement \& Health, 3(3), 123-129. 